\title{
Stapled vs Conventional Hand-sewn Gastrointestinal Anastomosis during Infancy: A Prospective Comparative Study from Central India
}

\author{
Arti S Mitra ${ }^{1}$, Unmed Chandak ${ }^{2}$, Kaushal K Kulkarni ${ }^{3}$, Nilesh Nagdive ${ }^{4}$, Rajendra Saoji ${ }^{5}$, Charu Tiwari ${ }^{6}$
}

\section{Abstract}

Background: The creation of a joint between two bowel ends in newborns and infants is one of the core surgical procedures in pediatric surgery. For a proper and perfect gastrointestinal (Gl) anastomosis, the factors to be considered are intraoperative duration, restoration of normal $\mathrm{Gl}$ function, effective hemostasis, reduction of tissue damage, and prevention of postoperative mortality and morbidity. The safety and efficacy of stapled GI tract anastomosis in adults have been extensively documented; however, available literature on the same is limited for infants.

Materials and methods: Fifty-six patients were divided into two groups-stapled group and hand-sewn group. Patients operated on both emergency and elective basis were included in the study. Hand-sewn anastomosis was done by either end-to-end single-layer or double-layer anastomosis. Suture material used for the anastomosis was Vicryl 3-0 or Vicryl 4-0. Stapled anastomosis was done by $55 \mathrm{~mm}$ linear cutting Gl stapler with side-to-side anastomosis.

Results: The present study included a total of 56 patients; there were 28 neonates and 28 infants; 37 of them were males. The most common clinical presentations were vomiting, abdominal distention, refusal to feed, and lethargy. The intraoperative duration in stapled $\mathrm{Gl}$ anastomosis was less when compared to hand-sewn anastomosis, so was the return of bowel activity and consequently early initiation of feeds and shorter hospital stay.

Conclusion: The present study favors stapled over hand-sewn Gl anastomosis in infancy in view of decreased intraoperative duration, reduced blood loss, early return of peristalsis, early initiation of feeds, and shorter duration of hospital stay. However, a small number of patients and lack of matching are the shortcomings of this study.

Keywords: Anastomosis, Gastrointestinal, Hand-sewn, Infants, Neonates, Stapled.

Euroasian Journal of Hepato-Gastroenterology (2020): 10.5005/jp-journals-10018-1308
\end{abstract}

\section{INTRODUCTION}

The creation of a joint between two bowel ends in newborns and infants is a central surgical procedure in the domain of pediatric surgeons. ${ }^{1}$ The fundamental aim of gastrointestinal $(\mathrm{Gl})$ anastomosis whether performed by hand-sewn or stapled technique is a good approximation of the tissues without tension and preserving its blood supply. For a proper and perfect Gl anastomosis, the factors to be considered are intraoperative duration, restoration of normal Gl function, effective hemostasis, reduction of tissue damage, and prevention of postoperative mortality and morbidity. An anastomotic leak often leads to sepsis, which adds to the morbidity of the patient, increases hospital stay, may require re-exploration, and may result in mortality.

The search for the most appropriate suture materials and suturing technique for $\mathrm{Gl}$ anastomosis is still a controversy, in both general and pediatric surgery. ${ }^{2}$ There are various suturing techniques (hand-sewn or stapled) and suture materials (natural or synthetic, monofilament or multifilament, absorbable or nonabsorbable) for $\mathrm{Gl}$ anastomosis.

Hand-sewn single-layer extramucosal GI anastomosis as described by Matheson of Aberdeen is being increasingly performed nowadays because of less tissue necrosis and luminal narrowing. ${ }^{3}$ Linear cutter GI staplers are capable of cutting and stapling the bowel at the same time, thereby avoiding the need for bowel clamping. The increased cost of the staplers is offset by a reduction in intraoperative time. Circular staplers have better

\footnotetext{
${ }^{1-3}$ Department of General Surgery, Government Medical College and Hospital, Nagpur, Maharashtra, India

4,5Department of Pediatric Surgery, Government Medical College and Hospital, Nagpur, Maharashtra, India

${ }^{6}$ Department of Paediatric Surgery, All India Institute of Medical Sciences, Raipur, Chhattisgarh, India
}

Address reprint requests to: Unmed Chandak, Department of General Surgery, Government Medical College and Hospital, Nagpur, Maharashtra, India, Phone: +91 9890493673, e-mail: uachandak@ gmail.com

How to cite this article: Mitra AS, Chandak U, Kulkarni KK, et al. Stapled vs Conventional Hand-sewn Gastrointestinal Anastomosis during Infancy: A Prospective Comparative Study from Central India. Euroasian J Hepato-Gastroenterol 2020;10(1):11-15.

Source of support: Nil

Conflict of interest: None

access in difficult areas like lower pelvic surgery, thereby sparing many patients from a permanent colostomy.

The safety and efficacy of stapled GI tract anastomosis in adults have been extensively documented. ${ }^{4}$ The use of a stapling device for bowel anastomosis minimizes tissue manipulation and trauma and leads to less bleeding and edema at anastomotic site and early return of bowel motility; consequently, there are less complications, early initiation of feeds and rapid patient recovery and less hospital 
stay. The major disadvantage of stapled $\mathrm{Gl}$ anastomosis is the cost of the staplers and the discrepancy between infantile bowel lumen and size of the instrument. ${ }^{5}$

Since the introduction of mechanical stapling devices and descriptions of stapling techniques by Steichen and Ravitch, stapled intestinal anastomoses have been widely used in adults, older infants, and children. ${ }^{6,7}$ However, the available literature on stapled $\mathrm{Gl}$ anastomosis in infants is limited. ${ }^{5}$ Talbert et al. first used the linear stapler (LDS) in pediatric patients in conjunction with Duhamel procedure, initially described by Martin and Altemeier. ${ }^{8,9}$ A functional end-to-end anastomosis was described by Steichen in 1968 , but the ability to use this accurate and rapid means to establish GI continuity has been limited by the size of the intestine in the neonates and small infants. ${ }^{5}$ In 1995 , Powell reported a series of seven successful intestinal anastomoses in infants younger than 4 months using mechanical staplers. ${ }^{10}$

In the present study, we present our experience in comparing the use of stapled vs conventional hand-sewn GI anastomosis in infants.

\section{Materials and Methods}

This prospective randomized case-control study was conducted in the Department of General Surgery and Pediatric Surgery at a tertiary institution in Central India from June 2017 to November 2019. Approval was sought from the Institutional Ethics Committee. The study included all infants (under 1 year age) who underwent $\mathrm{Gl}$ resection and anastomosis during elective as well as emergency surgeries. Infants undergoing colostomy closure were also included. Infants undergoing esophageal anastomosis, correction of anorectal malformations, and laparoscopic procedures were excluded as well as those who were operated outside the institution.

A total of 56 infants satisfying the above inclusion criteria were included in this study and were divided into two groups-the study group included infants undergoing stapled $\mathrm{Gl}$ anastomosis and the control group included infants undergoing hand-sewn $\mathrm{Gl}$ anastomosis. Randomization of patients to either of these two groups was done by allotting patients to each group alternately.

All patients were admitted, and after taking written and informed consent from parents, their detailed clinical presentations, investigations, diagnosis, procedure performed, and outcome were recorded in the pre-set proforma. All patients were empirically started on broad-spectrum antibiotics, and dosage was decided according to the weight of the patients. After preoperative investigations, indicated patients were taken up for surgical intervention. The procedures were performed by consultant surgeons to eliminate bias due to operating surgeons.

Hand-sewn anastomosis was done by delayed absorbable sutures in either end-to-end single-layer or double-layer manner. Patients in the study group underwent side-to-side GI anastomosis using a $55 \mathrm{~mm}$ linear cutting $\mathrm{Gl}$ stapler.

All patients were carefully monitored, and comparison was done between the two groups with respect to intraoperative duration, blood loss, postoperative return of bowel sounds (peristaltic activity), time of initiation of oral feeds, complicationsanastomotic leak and surgical site infection (SSI), total duration of hospital stay, outcome, and follow-up.

\section{Observations and Results}

A total of 56 patients were included in this study. The demographics of the patients have been summarized in Table 1. There were
Table 1: Demographic characteristics of patients in both the groups

\begin{tabular}{|c|c|c|c|c|}
\hline S. no & & Parameters & $\begin{array}{l}\text { Stapled } \\
\text { group }\end{array}$ & $\begin{array}{l}\text { Hand-sewn } \\
\text { group }\end{array}$ \\
\hline \multirow[t]{3}{*}{1} & \multirow[t]{3}{*}{ Age distribution } & Mean (months) & 8.89 & 8.39 \\
\hline & & $\begin{array}{l}\text { No. of } \\
\text { neonates ( }<28 \\
\text { days) }\end{array}$ & 14 & 14 \\
\hline & & No. of infants & 14 & 14 \\
\hline \multirow[t]{2}{*}{2} & \multirow{2}{*}{$\begin{array}{l}\text { Gender } \\
\text { distribution }\end{array}$} & Females & 12 & 7 \\
\hline & & Males & 16 & 21 \\
\hline 3 & $\begin{array}{l}\text { Mean weight } \\
(\mathrm{kg})\end{array}$ & & 4.11 & 3.85 \\
\hline \multirow[t]{5}{*}{4} & $\begin{array}{l}\text { Clinical } \\
\text { presentation }\end{array}$ & $\begin{array}{l}\text { Abdominal } \\
\text { distention }\end{array}$ & 17 & 16 \\
\hline & & Vomiting & 22 & 19 \\
\hline & & Irritability & 6 & 8 \\
\hline & & $\begin{array}{l}\text { Decreased } \\
\text { intake }\end{array}$ & 22 & 15 \\
\hline & & Fever & 9 & 9 \\
\hline
\end{tabular}

Table 2: Diagnosis of patients in both the groups

\begin{tabular}{|c|c|c|c|}
\hline S. no & Diagnosis & Stapled group & $\begin{array}{l}\text { Hand-sewn } \\
\text { group }\end{array}$ \\
\hline 1 & Jejunal atresia & 7 & 5 \\
\hline 2 & Ileal atresia & 4 & 3 \\
\hline 3 & Duodenal atresia & 6 & 5 \\
\hline 4 & Patent vitellointestinal duct & 2 & 2 \\
\hline 5 & Meckel's diverticulum & 1 & 2 \\
\hline 6 & Gastroschisis & 1 & 0 \\
\hline 7 & Ileostomy closure & 1 & 1 \\
\hline 8 & Total colonic aganglionosis & 1 & 1 \\
\hline 9 & Hirschsprung's disease & 1 & 1 \\
\hline 10 & Intussusception & 4 & 2 \\
\hline 11 & Ileal perforation & 0 & 3 \\
\hline 12 & Obstructed umbilical hernia & 0 & 1 \\
\hline
\end{tabular}

28 neonates and 28 infants; 37 were males (66\%) and 19 were females (34\%). The mean weight (in $\mathrm{kg}$ ) was $4.11 \mathrm{~kg}$ in the study group and $3.85 \mathrm{~kg}$ in the control group. The most common presenting complaints were vomiting ( $n=41,73.2 \%)$, decreased intake of feeds ( $n=37,66.1 \%)$, abdominal distension ( $n=33,59 \%)$, and obstipation ( $n=22,39.3 \%) ; 14$ patients presented with irritable behavior and 19 patients had fever on presentation; 4 patients had history of passing red currant jelly stools and 2 patients had history of passing stools with difficulty.

The final diagnosis of the patients in both the groups has been summarized in Table 2 . The commonest diagnosis was congenital small bowel atresia (including duodenal, jejunal, and ileal) with 17 patients in the study group and 13 patients in the control group. Comorbidities were present in three patients - two patients from the study group-Down's facies with VSD in one patient and large ostium secundum ASD in another patient; 1 patient from the control group had large ASD.

The comparison of intraoperative and postoperative parameters between the two groups has been summarized in Table 3. The mean total operative time was 65.71 minutes in the study group and 69.89 minutes in the control group; the time taken for anastomosis was 
Table 3: Comparison of outcome parameters between the two groups

\begin{tabular}{|c|c|c|c|c|c|}
\hline$S / N$ & Parameters & & Stapled group & Hand-sewn group & $p$ value \\
\hline \multirow[t]{2}{*}{1} & \multirow[t]{2}{*}{ Intraoperative duration } & $\begin{array}{l}\text { Anastomosis duration } \\
\text { (mean in min) }\end{array}$ & 23.92 & 33.14 & $<0.00001$ \\
\hline & & $\begin{array}{l}\text { Total operative duration } \\
\text { (mean in min) }\end{array}$ & 65.71 & 69.89 & 0.017 \\
\hline 2 & $\begin{array}{l}\text { Intraoperative blood loss (mean } \\
\text { in } \mathrm{mL} \text { ) }\end{array}$ & & 22.67 & 27.78 & 0.027 \\
\hline \multirow[t]{3}{*}{3} & \multirow[t]{3}{*}{ Postoperative complications } & Anastomotic leak & 4 & 3 & 0.504 \\
\hline & & Surgical site infection & 2 & 5 & 0.54 \\
\hline & & Sepsis & 8 & 6 & 0.67 \\
\hline \multirow[t]{2}{*}{4} & \multirow{2}{*}{$\begin{array}{l}\text { Initiation of feeds (mean } \\
\text { postoperative days) }\end{array}$} & NG feeds & 4.61 & 22.67 & 0.01 \\
\hline & & Oral feeds & 5.39 & 7 & 0.01 \\
\hline 5 & Mean hospital stay (days) & & 6.71 & 8.71 & 0.001 \\
\hline
\end{tabular}

23.92 minutes in the study group and 33.14 minutes in the control group. The difference in both durations was statistically significant with $p$ value of $<0.05$. The average blood loss was $23.92 \mathrm{~mL}$ in the study group and $27.78 \mathrm{~mL}$ in the control group, $p$ value being 0.027 which is statistically significant.

Anastomotic leak was seen in four patients in the study group and three patients in the control group. Among the four patients in the study group, three patients required re-exploration; two of these recovered and were discharged, while one patient died during postoperative period. One patient recovered by conservative management. In the control group, all three patients with anastomotic leak required re-exploration; one of these recovered and was discharged, while two patients expired. Surgical site infection (SSI) was seen in two patients from the study group and five patients in the control group. A total of 14 patients developed sepsis -8 in the study group and 6 in the control group. The differences in these postoperative complications were not statistically significant.

Patients in the study group tolerated feeds early, and the difference between the two groups was statistically significant ( $p$ value $<0.05$ ). The mean hospital stay was also less in the study group (6.71 days vs 8.71 days) which was statistically significant ( $p$ value $<0.05)$.

There were a total of seven deaths-five from the stapled group and two from the hand-sewn group ( $p$ value: 0.225 ), cause being septicemia in both the groups. The remaining patients have no complaints on follow-up.

\section{Discussion}

Surgical stapling devices were first introduced by Hultl, Hummer (Budapest) in 1908, but their use has increased recently since the introduction of new and reliable disposable instruments in the past 30 years. ${ }^{11}$ Lim et al. confirmed the presence of foreign body reaction in stapled human $\mathrm{Gl}$ anastomoses, the source of foreign materials eliciting this reaction being stapler cartridges. ${ }^{12}$ Among the American and European surgeons who were trained in surgery at the end of the twentieth century, staplers were called "Russian Gun".13

However, the available literature fails to demonstrate the superiority of stapled over hand-sewn techniques in colorectal anastomosis, regardless of the level of anastomosis, although a high stricture rate was noted with the former technique. The decision of the preferable technique must be judged on the basis of previous experience, clinical circumstances, and available resources. ${ }^{14}$ Cochrane review of seven trials found fewer leaks after stapled anastomosis with no differences in operative time or the incidence of stricture or wound infection. ${ }^{15}$ In addition, a meta-analysis studied 13 trials that reported no differences in mortality and leakage rate after stapling usage. ${ }^{16}$

In 2011, Mitchell et al. reported a series of using staplers in 64 small children with phenomenal postoperative results excluding leaks. ${ }^{17}$ He concluded that the stapled anastomosis is an effective alternative for restoration of bowel discontinuity in newborns and small babies when permitted by intestinal size. ${ }^{17}$

Table 4 summarizes the various parameters compared in our study with recent similar studies. ${ }^{1,18,19}$

A total of 56 infants were included in the present study, with the average age of patients undergoing stapled anastomosis being 8.89 months and those undergoing conventional hand-sewn anastomosis being 8.32 months. The number of male patients is more as compared to female patients in our study. This may be due to the overall gender ratio in our country, or also due to negligence toward the female child. The average weight of the patients in the study group was $4.11 \mathrm{~kg}$ which was similar as compared to $3.85 \mathrm{~kg}$ in the control group. These parameters are comparable to recent similar studies by Hintz et al. (10.5 months for the stapled group and 8.9 months for the hand-sewn group); Kozlov et al., however, reported their findings on younger infants (1.93 months for the stapled group and 1.64 months for the hand-sewn group), and Sato et al. reported their findings in older children ( $0-13$ years with a mean of 20 months). ${ }^{1,18,19}$

The mean intraoperative anastomotic time in our study was 23.92 minutes for the stapled group when compared to 33.14 minutes for the hand-sewn group. The total operative duration was 65.71 minutes in the stapled group as compared to 69.89 minutes in the hand-sewn group. This was comparable to similar studies by Hintz et al., Sato et al., and Kozlov et al. as described in Table 4.,18,19

In the present study, nasogastric feeds could be started on an average of 4.61 postoperative day in the stapler group as compared to 6.07 postoperative day in the hand-sewn group. The patients were started on oral feds on an average 5.39 postoperative day in the stapler group and 7 postoperative day in the hand-sewn group. In the Hintz et al. study, the median time to initial and full feeds was 5 and 11 days in the stapled group and 3 and 7 days in the handsewn group, respectively. ${ }^{18}$ Kozlov et al. reported that mean time 
Stapled vs Conventional Hand-sewn Gastrointestinal Anastomosis during Infancy

\begin{tabular}{|c|c|c|c|c|c|c|}
\hline S. no & Parameters & Groups & Hintz et al. (2018) & Kozlov et al. (2013) & Sato et al. & Present study \\
\hline \multirow[t]{2}{*}{1} & \multirow[t]{2}{*}{ Mean age (months) } & Stapled & 10.5 & 1.93 & 20 & 8.89 \\
\hline & & Hand-sewn & 8.9 & 1.64 & - & 8.32 \\
\hline \multirow[t]{2}{*}{2} & \multirow[t]{2}{*}{ Mean weight $(\mathrm{kg})$} & Stapled & 8.2 & 2.72 & 10.3 & 4.11 \\
\hline & & Hand-sewn & 8 & 2.88 & - & 3.85 \\
\hline \multirow[t]{2}{*}{3} & \multirow{2}{*}{$\begin{array}{l}\text { Mean intraoperative } \\
\text { duration (minutes) }\end{array}$} & Stapled & 127 & 56.4 & 74.8 & 65.71 \\
\hline & & Hand-sewn & 107 & 77.4 & 95.7 & 69.89 \\
\hline \multirow[t]{2}{*}{4} & \multirow[t]{2}{*}{$\begin{array}{l}\text { Mean POD to start feeds } \\
\text { (days) }\end{array}$} & Stapled & 11 & 6.7 & $\begin{array}{l}3.7 \text { (ileal atresia), } 4 \\
\text { (colostomy closure) }\end{array}$ & 5.39 \\
\hline & & Hand-sewn & 7 & 6.7 & $\begin{array}{l}8.5 \text { (ileal atresia), } 6.2 \\
\text { (colostomy closure) }\end{array}$ & 7 \\
\hline \multirow[t]{2}{*}{5} & \multirow[t]{2}{*}{$\begin{array}{l}\text { Mean duration of hospital } \\
\text { stay (days) }\end{array}$} & Stapled & 11 & 14.1 & $\begin{array}{l}12.3 \text { (ileal atresia), } 11.8 \\
\text { (colostomy closure) }\end{array}$ & 6.71 \\
\hline & & Hand-sewn & 7 & 13.3 & $\begin{array}{l}21.6 \text { (ileal atresia), } 16.1 \\
\text { (colostomy closure) }\end{array}$ & 8.71 \\
\hline
\end{tabular}

to full enteral feeding for patients with stapled anastomosis was isochronous for patients with standard hand-sewn technique (6.7 vs 6.7 days; $p=0.926){ }^{1}$

In the present study, anastomotic leak was seen in a total of seven patients-four patients in the study group and three patients in the control group. A total of seven patients-two from the stapler group and five from the hand-sewn group-developed surgical site infection ( $p$ value 0.504). Fourteen patients-eight patients in the study group and six patients in the control groupdeveloped sepsis in the postoperative period ( $p$ value 0.54 ). None of the patients in our study developed anastomotic stricture in the postoperative period or on follow-up later.

In the Hintz et al. study, there were a total of 20 anastomotic complications: 11 with strictures alone ( 2 in the stapled group and 9 in the hand-sewn group), 3 with leaks alone (1 in the stapled group and 2 in the hand-sewn group), and 6 with both a leak and a stricture ( 1 in the stapled group and 5 in the hand-sewn group). ${ }^{18}$

The average duration of hospital stay for all procedures was 6.71 days in the stapled group as compared to 8.71 days in the hand-sewn group in the present study. In a study by Hintz et al., the median duration of hospital stay was 11 days for the stapled group as compared to 11 days for the hand-sewn group which was not significant. ${ }^{18}$ Similar findings were reported by Kozlov et al. ${ }^{1}$

There were a total of seven deaths-five from the stapled group and two from the hand-sewn group ( $p$ value: 0.225 ), cause being septicemia in both the groups. Four of these total patients (two from each group) died after re-exploration for anastomotic leak. There were no deaths observed in other studies.,18,19

However, the main disadvantage of using stapled devices is its cost. As the study was conducted in a government setup, the cost has not been analyzed. This study has limitations as well - the small number of patients and that the study and control groups were not matched with respect to age, weight, and diagnosis of the patients.

\section{Conclusion}

The present study favors stapled anastomosis in infants with respect to less operative time duration, reduced blood loss, early start of feeds, and shorter duration of hospital stay. However, a larger sample size is necessary to draw definitive conclusions.

\section{References}

1. Kozlov Y, Novogilov V, Podkamenev A, et al. Stapled bowel anastomoses in newborn surgery. Eur J Pediatr Surg 2013;23(1):63-66. DOI: 10.1055/s-0032-1326952.

2. Neutzling $C B$, Lustosa $S A$, Proenca IM, et al. Stapled vs handsewn methods for colorectal anastomosis surgery. Cochrane Database Syst Rev 2012;15(2):CD003144.

3. Damesha N, Lubana P, Jain D, et al. A comparative study of sSutured and stapled anastomosis in gastrointestinal operations. Int J Surg 2007;15(2).

4. Shelygin YA, Chernyshov SV, Rybakov EG. Stapled ileostomy closure results in reduction of postoperative morbidity. Tech Coloproctol 2010;14(1):19-23. DOI: 10.1007/s10151-009-0550-y.

5. Steichen FM. The use of staplers in anatomical side-to-side and functional end-to-end enteroanastomoses. Surgery 1968;64(5): 948-953.

6. Steichen FM, Ravitch MM. Mechanical sutures in surgery. Br J Surg 1993;60(3):191-197. DOI: 10.1002/bjs.1800600307.

7. Steichen FM, Ravitch MM. Stapling in surgery. Chicago, IL: Year Book Medical; 1984. DOI: 10.1097/00000658-198408000-00017.

8. Talbert JL, Seashore SH, Ravitch MM. Evaluation of modified Duhamel operation for correction of Hirschsprung's disease. Ann Surg 1974;179(5):671-675. DOI: 10.1097/00000658-197405000-00021.

9. Martin LW, Altemeier WA. Clinical experience with a new operation (modified Duhamel procedure) for Hirschsprung's disease. Ann Surg 1962;156(4):678-681. DOI: 10.1097/00000658-196210000-00014.

10. Powell RW. Stapled intestinal anastomosis in neonates and infants: use of the endoscopic intestinal stapler. J Pediatr Surg 1995;30(2): 195-197. DOI: 10.1016/0022-3468(95)90559-6.

11. Mortensen NJ, Ashraf S. Intestinal Anastomosis In Section 5 Gastrointestinal Tract and Abdomen 2008.

12. Lim CB, Goldin RD, Darzi A, et al. Characterization of materials eliciting foreign body reaction in stapled human gastrointestinal anastomoses. Br J Surg 2008;95(8):1044-1050. DOI: 10.1002/ bjs.6071.

13. Baker RS, Foote J, Kemmeter $P$, et al. The science of stapling and leaks. Obes Surg 2004;14(10):1290-1298. DOI: 10.1381/0960892042583888.

14. Ho YH, Ashour MAT. Techniques for colorectal anastomosis. World J Gastroenterol 2010;16(13):1610-1621. DOI: 10.3748/wjg.v16.i13. 1610.

15. Choy PY, Bissett IP, Docherty JG, et al. Stapled vs handsewn methods for ileocolic anastomosis. Cochrane Database Syst Rev 2011;7(9):CD004320. 
16. MacRae HM, McLeod RS. Handsewn vs stapled anastomoses in colon and rectal surgery: a meta-analysis. Dis Colon Rectum 1998;41(2): 180-189. DOI: 10.1007/BF02238246.

17. Mitchell IC, Barber R, Fischer AC, et al. Experience performing 64 consecutive stapled intestinal anastomoses in small children and infants. J Pediatr Surg 2011;46(1):128-130. DOI: 10.1016/ j.jpedsurg.2010.09.076.
18. Hintz GC, Alshehri A, Bell CM, et al. Stapled vs hand-sewn pediatric intestinal anastomoses: a retrospective cohort study. J Pediatr Surg 2018;53(5):959-963. DOI: 10.1016/j.jpedsurg.2018.02.021. Epub 2018 Feb 8.

19. Sato $\mathrm{K}$, Uchida $\mathrm{H}$, Tanaka $\mathrm{Y}$, et al. Stapled intestinal anastomosis is a simple and reliable method for management of intestinal caliber discrepancy in children. Pediatr Surg Int 2012;28(9):893-898. DOI: 10.1007/s00383-012-3146-y. PMID: 22864546; PMCID: PMC3433672. 